\section{OPEN ACCESS}

Edited by:

Piotr Jablonski,

Seoul National University,

South Korea

Reviewed by:

Todd Jason McWhorter,

University of Adelaide, Australia

Piotr Matyjasiak,

Cardinal Stefan Wyszyński University,

Poland

${ }^{*}$ Correspondence: Ivan Maggini

ivan.maggini@vetmeduni.ac.at

Specialty section:

This article was submitted to Behavioral and Evolutionary Ecology,

a section of the journal

Frontiers in Ecology and Evolution

Received: 03 May 2021

Accepted: 12 July 2021

Published: 02 August 2021

Citation:

Paces B, Waringer BM, Domer A,

Burns D, Zvik Y, Wojciechowski MS, Shochat E, Sapir N and Maggini I (2021) Evaporative Water Loss and Stopover Behavior in Three Passerine Bird Species During Autumn Migration.

Front. Ecol. Evol. 9:704676. doi: $10.3389 /$ fevo.2021.704676

\title{
Evaporative Water Loss and Stopover Behavior in Three Passerine Bird Species During Autumn Migration
}

\begin{abstract}
Bernhard Paces', Barbara M. Waringer', Adi Domer', Darren Burns ${ }^{2}$, Yoram Zvik 2,3, Michał S. Wojciechowski ${ }^{4}$ Eyal Shochat ${ }^{2}$, Nir Sapir ${ }^{5}$ and Ivan Maggini6*

1 Division of Tropical Ecology and Animal Biodiversity, Department of Botany and Biodiversity Research, Faculty of Life Sciences, University of Vienna, Vienna, Austria, ${ }^{2}$ Department of Life Sciences, Ben-Gurion University of the Negev, Beersheba, Israel, ${ }^{3}$ Hoopoe Ornithology \& Ecology Center, Yeroham, Israel, ${ }^{4}$ Department of Vertebrate Zoology and Ecology, Faculty of Biological and Veterinary Sciences, Nicolaus Copernicus University, Toruń, Poland, ${ }^{5}$ Department of Evolutionary and Environmental Biology, and Institute of Evolution, University of Haifa, Haifa, Israel, ${ }^{6}$ Konrad-Lorenz Institute of Ethology, University of Veterinary Medicine Vienna, Vienna, Austria
\end{abstract}

Migratory birds are often not specifically adapted to arid conditions, yet several species travel across deserts during their journeys, and often have more or less short stopovers there. We investigated whether differences in thermoregulatory mechanisms, specifically evaporative cooling, explain the different behavior of three passerine species while stopping over in the Negev desert, Israel. We measured cutaneous water loss (CWL) under ambient conditions and the temperature of panting onset in an experimental setup. In addition, we performed behavioral observations of birds at a stopover site where we manipulated water availability. Blackcaps had slightly higher CWL at relatively low temperatures than Willow Warblers and Lesser Whitethroats. When considered relative to total body mass, however, Willow Warblers had the highest CWL of the three species. Blackcaps started panting at lower ambient temperature than the other two species. Taken together, these results suggest that Willow Warblers are the most efficient in cooling their body, possibly with the cost of needing to regain water by actively foraging during their staging. Lesser Whitethroats had a similar pattern, which was reflected in their slightly higher levels of activity and drinking behavior when water was available. However, in general the behavior of migratory species was not affected by the availability of water, and they were observed drinking rather rarely. Our results indicate that differences in thermoregulatory mechanisms might be at the basis of the evolution of different stopover strategies of migratory birds while crossing arid areas such as deserts.

Keywords: Negev, thermoregulation, panting, cutaneous water loss, water availability

\section{INTRODUCTION}

Thermoregulation in desert habitats is a challenge for endothermic animals. When ambient temperatures $\left(T_{a}\right)$ exceed body temperature $\left(T_{b}\right)$, they need to dissipate excess heat produced endogenously as well as gained from the environment to regulate $\mathrm{T}_{\mathrm{b}}$. Consequently, several behavioral and physiological strategies have evolved among desert-living animals to cope with 
these conditions. Behavioral strategies include avoiding exposure to excessive heat by e.g., living in burrows, or being active when temperatures are not at their maximum (Yousef and Dill, 1971; Abáigar et al., 2018; Whitford and Duval, 2020). The only way to dissipate body heat at $\mathrm{T}_{\mathrm{a}}>\mathrm{T}_{\mathrm{b}}$ is to evaporate water from body surfaces (Dawson, 1982), but since water is scarce in the desert, several mechanisms have evolved in desert species to reduce evaporative water loss and avoid dehydration (King and Farner, 1961; Louw, 1993; Williams and Tieleman, 2005; Donald and Pannabecker, 2015). In birds, evaporative cooling is primarily achieved through cutaneous water loss (CWL) and respiratory water loss (RWL) (Whittow, 1986; Williams and Tieleman, 2005; McKechnie and Wolf, 2019). The proportion of CWL and RWL to total evaporative water loss (TEWL) varies among species, but it is generally around $50 \%$ at moderate $\mathrm{T}_{\mathrm{a}}$ 's (Wolf and Walsberg, 1996; Tieleman and Williams, 2002; Ro and Williams, 2010). When $\mathrm{T}_{\mathrm{a}}$ approaches or exceeds $\mathrm{T}_{\mathrm{b}}$, birds increase both cutaneous and respiratory water loss, but the latter to a greater extent (Wolf and Walsberg, 1996; Tieleman and Williams, 2002; Wojciechowski et al., 2021). With the exception of Columbiforms (McKechnie and Wolf, 2004), respiratory water loss is the main avenue of water loss when a bird is exposed to heat stress (Wolf and Walsberg, 1996; Tieleman and Williams, 2002; Wojciechowski et al., 2021). Birds experiencing high rates of TEWL may have difficulties to keep their body adequately hydrated while maintaining body temperature below critical hyperthermia (Webster, 1991). Thus, it becomes an obvious challenge, especially for diurnal birds, to reduce TEWL while preventing lethal hyperthermia (McKechnie and Wolf, 2010; Conradie et al., 2020). Tolerance of hyperthermia is the primary physiological mechanism allowing for water conservation in heat exposed birds (Calder and King, 1974; Weathers, 1981; McKechnie and Wolf, 2019). It has been shown that desert birds have a lower TEWL than species from mesic areas (Williams, 1996). CWL is reduced through a specific lipid composition of the skin's stratum corneum, which makes it less permeable to endogenous water (Tieleman and Williams, 2002; Haugen, 2003; Haugen et al., 2003; Muñoz-Garcia and Williams, 2011; Champagne et al., 2012). A reduction of RWL in desert birds as a mechanism of water conservation has been discussed (Williams and Tieleman, 2005) and was observed in zebra finches (Taeniopygia guttata) acclimated to limited water availability (Wojciechowski et al., 2021). However, in the Kalahari Desert, bird species relying on food as their only water source started panting at a higher temperature and have overall higher evaporative scope when compared with species that drink water (Smit et al., 2016; Czenze et al., 2020). The ambient temperature of panting onset potentially sets the time boundaries in which a bird can remain active during the day in a desert environment, while avoiding the excessive water loss induced by RWL for thermoregulation at higher $\mathrm{T}_{\mathrm{a}}$ (Weathers, 1981; Smit et al., 2016; Pattinson et al., 2020).

Besides local desert specialists, many temperate-zone birds stage in the desert for a relatively short time during migration. In the European-African migration system, around 2.1 billion passerine and near-passerine birds cross the Sahara Desert during their autumn migration to reach their wintering grounds
(Moreau, 1972; Hahn et al., 2009). These birds presumably did not evolve specific adaptations to the extremely arid climate conditions of the desert, yet most songbirds do not overfly the Sahara in one non-stop flight, but rather fly at night and stop over during the day (Biebach, 1985; Bairlein, 1988; Schmaljohann et al., 2007). Notably, many species avoid long stopovers in the desert and prolong their flights as much as possible (Adamík et al., 2016; Jiguet et al., 2019; Malmiga et al., 2021). Nonetheless, these trans-Saharan migrants are known to perform longer stopovers prior to the desert crossing during autumn (Yosef and Chernetsov, 2005). Specifically, many migrating birds stop in the Negev desert which is located at the northern edge of the Sahara Desert (Moreau, 1972; Yosef and Chernetsov, 2005). Despite being defined as an arid environment (Goldreich, 2012), the Negev is the last potential stopover area before the Sahara Desert crossing during autumn. Birds that stage at the desert edge are staging for longer periods, accumulating large amounts of fat to facilitate the cross-desert travel (Piersma, 1998; Schaub and Jenni, 2000; Wojciechowski et al., 2014). Observational studies showed that the behavior at desert stopover sites varies among species (Jenni-Eiermann et al., 2011; Arizaga et al., 2013; Hama et al., 2013; Maggini et al., 2015). These differences are likely associated with adaptations to arid habitats: while xerophilic species (e.g., many Mediterranean species) spend longer stopovers in the desert and effectively refuel, mesophilic species usually avoid long stopovers and spend rather short time on the ground resting in the shade (Jenni-Eiermann et al., 2011).

The difference in stopover patterns between xerophilic and mesophilic migratory species may result from differences in their ability to maintain water balance. Foraging behavior and fat accumulation of migratory Blackcaps (Sylvia atricapilla, a mesophilic species) at a desert stopover site was influenced by water availability, while this was not the case in Lesser Whitethroats (Sylvia curruca, a xerophilic species) (Sapir et al., 2004; Tsurim et al., 2008). In addition, Lesser Whitethroats were able to accumulate energy stores in a similar fashion in a wide range of habitats, while in Blackcaps this was restricted to a habitat offering ideal feeding conditions, such as high amounts of lipid-rich fruits (Sapir et al., 2004; Domer et al., 2018).

In this study, we aimed at understanding the physiological mechanisms underlying the different behavior of birds at desert stopovers in relation to water availability and their ability to maintain water balance. We hypothesized that trans-Saharan migratory songbird species adjust their stopover behavior in the desert to minimize the risk of dehydration. We assumed that species better adapted to arid conditions face lower risk of dehydration. In particular, we predicted that species actively refueling at a stopover in the Negev have a lower surface-specific CWL and express a higher temperature threshold for panting onset than species which spend their stopover resting in the shade. We also predicted that an experimental manipulation of water availability leads to a change in foraging behavior, especially in species with low refueling rates, inducing an increase in refueling when water was available. To test these predictions, we quantified foraging and drinking behavior, CWL, and temperature of panting onset in Blackcaps and Lesser Whitethroats, taking advantage of the previous knowledge of 
their different stopover strategies during autumn migration in Israel (Sapir et al., 2004; Tsurim et al., 2008). We also measured CWL and panting onset in the Willow Warbler (Phylloscopus trochilus). This species is regularly observed to actively forage at desert stopover sites in spring (Jenni-Eiermann et al., 2011; Maggini et al., 2015). If indeed differences in thermoregulatory CWL underlie differences in stopover behavior among species, Blackcaps should have a higher CWL and a lower temperature of panting onset than the other two species. The augmented availability of drinking water should increase foraging activity in all species, but more so in Blackcaps.

\section{MATERIALS AND METHODS}

\section{Study Site}

We collected data during the autumns of 2017 and 2018 at two stopover sites in the Negev Desert, Israel (Figure 1). In 2017,

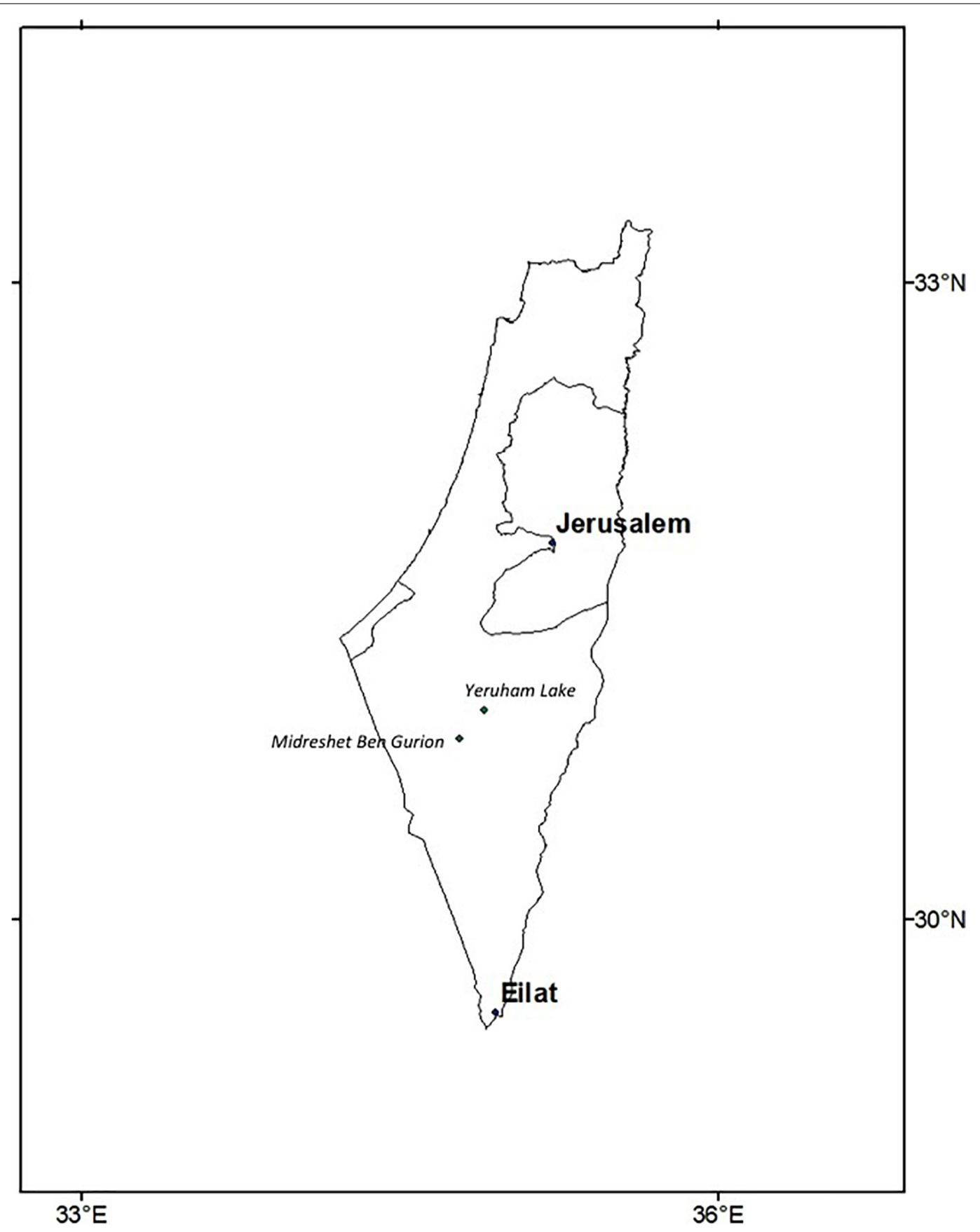

FIGURE 1 | The location of the two field sites in Israel. The study was conducted at Lake Yeruham in 2017, and at Midreshet Ben-Gurion in 2018. 
our study site was Lake Yeruham $\left(30^{\circ} 59^{\prime} \mathrm{N}, 34^{\circ} 53^{\prime} \mathrm{E}\right)$, a large artificial waterbody in the northern Negev. The vegetation was dominated by Phragmites australis, Tamarix aphylla, and Tamarix nilotica as well as Xanthium strumarium. At some distance from the lakeshore, the most common plant species were Acacia raddiana, Atriplex halimus, Morus sp., and P. australis. During autumn 2018 we collected data at Midreshet Ben-Gurion $\left(30^{\circ} 51^{\prime} \mathrm{N}, 34^{\circ} 46^{\prime} \mathrm{E}\right)$, approximately $19 \mathrm{~km}$ south of the 2017 site. This site includes an experimental mixed Pistacia tree plantation (1.7 ha) which is populated mainly with two species, Pistacia lentiscus and Pistacia chinensis, in addition to Acacia saligna and A. halimus.

\section{Study Species}

We studied Blackcaps, Lesser Whitethroats and Willow Warblers. These three species differ in body mass and size (Shirihai and Svensson, 2018; own data in Table 1) and have similar breeding origins (Yosef Kiat, Israeli Bird Ringing Center, unpubl. data). Blackcaps and Willow Warblers winter mainly in forested areas, although they are both highly flexible in their habitat selection (Snow et al., 1997; Shirihai et al., 2001; Sapir et al., 2004; Baker, 2010). Even though both species use similar habitats, they have different refueling strategies: migratory Blackcaps rely mainly on pre-departure fattening rather than refueling in desert oases especially during autumn migration (Izhaki and Maitav, 1998; Sapir et al., 2004; Tsurim et al., 2008; Wojciechowski et al., 2014), and Willow Warblers spend more time foraging en route and carry relatively low fuel loads (Jenni-Eiermann et al., 2011; Haran and Izhaki, 2013; Maggini et al., 2015). The preferred winter habitats of Lesser Whitethroats are savannas with scattered trees or thornbush savanna (Snow et al., 1997; Shirihai et al., 2001; Sapir et al., 2004). The refueling strategy of Lesser Whitethroats is not thoroughly studied, but they show positive refueling rates in the region of our study (Sapir et al., 2004).

\section{Field CWL Measurements}

To quantify differences in evaporative water loss among bird species we conducted CWL measurements at Midreshet BenGurion during autumn 2018. Birds were captured using mist nets. Captures started at 5:30 AM and were stopped when ambient temperature exceeded $30^{\circ} \mathrm{C}$. Captured birds were marked with aluminum leg ring, after which the length of the folded wing and body mass were measured using international standards (Bairlein, 1995). Then, the birds were kept in a cotton bag in a shaded location until CWL measurements were taken.

TABLE 1 | Mean body mass and wing length (mean $\pm 1 \mathrm{SD}$ ) of the three species measured in this study.

\begin{tabular}{lcc}
\hline Species & Body mass $(\mathbf{g})$ & Wing length (mm) \\
\hline Blackcap (S. atricapilla, $n=205)$ & $17.9 \pm 2.5$ & $76.7 \pm 2.0$ \\
Lesser Whitethroat (S. curruca, $n=118)$ & $12.7 \pm 1.7$ & $67.0 \pm 2.1$ \\
Willow Warbler (P. trochilus, $n=134)$ & $9.0 \pm 1.1$ & $67.2 \pm 3.2$
\end{tabular}

The sample size refers to all birds measured with respirometry in 2017 and with the vapometer in 2018.

Sample sizes differ from later analyses because of the exclusion of birds showing no changepoint in the analysis of panting onset.
At the beginning of each measurement, we recorded time, air temperature, and air humidity using a mobile digital thermohygrometer (NeKan EU). Relative humidity ( $\mathrm{RH}$, in \%) was transformed to absolute humidity ( $\mathrm{AH}$, in $\mathrm{g} \mathrm{H}_{2} \mathrm{O} \mathrm{m}^{-3}$ ) using the formula $\mathrm{AH}=\mathrm{C} \times \mathrm{P}_{\mathrm{w}} / \mathrm{T}$, where $\mathrm{C}$ is a constant of 2.16679 $\left(\mathrm{gK} \mathrm{J}^{-1}\right), \mathrm{P}_{\mathrm{w}}$ is the partial pressure of water vapor in $\mathrm{Pa}$, and $\mathrm{T}$ is the temperature in $\mathrm{K}$. We calculated $\mathrm{P}_{\mathrm{w}}$ as $\mathrm{P}_{\mathrm{ws}}$ (saturation water vapor pressure in $\mathrm{hPa}) \times \mathrm{RH}$. $\mathrm{P}_{\mathrm{ws}}$ was obtained using the formula $\mathrm{P}_{\mathrm{ws}}=\mathrm{A} \times 10^{\wedge}\left[\mathrm{m} \times \mathrm{T} /\left(\mathrm{T}+\mathrm{T}_{\mathrm{n}}\right)\right]$, where $\mathrm{A}, \mathrm{m}$ and $\mathrm{T}_{\mathrm{n}}$ are constants (respectively, 6.1164341, 7.591386, and 240.7263 for temperatures between $-20^{\circ} \mathrm{C}$ and $+50^{\circ} \mathrm{C}$ ), and $\mathrm{T}$ was the temperature in ${ }^{\circ} \mathrm{C}$.

The measurement was made by an experimenter who exposed at least $50 \mathrm{~mm}^{2}$ of the lateral body apterium under the bird's left wing, while wearing latex gloves to avoid moistening of the bird's skin by human sweat. Then, five subsequent measurements of surface-specific CWL were taken using a factory-calibrated VapoMeter ${ }^{\text {TM }}$ (Delfin Technologies, Ltd., Kuopio, Finland, hereafter: vapometer; du Plessis et al., 2013). We used the small adapter of the vapometer, which covers $16 \mathrm{~mm}^{2}$ of skin (MuñozGarcia and Williams, 2007; Muñoz-Garcia et al., 2012), and each measurement took about 20-30 s. The whole procedure lasted between 7 and $10 \mathrm{~min}$, and immediately afterward the birds were released at the site of capture. Visual fat score (Kaiser, 1993) was assessed after the vapometer measurement to avoid blowing moist air onto the bird's skin.

\section{Temperature of Panting Onset}

This part of the study was conducted at Lake Yeruham during autumn 2017. Birds were captured using mist nets from 5:30 AM until at least five individuals of the study species were caught. Captured birds were marked and measured as described above.

We used a flow-through respirometry protocol to measure the temperature of panting onset. A bird was placed into a twocompartment respirometry chamber (Wolf and Walsberg, 1996) with which we intended to measure CWL and RWL separately. The upper section of the chamber (head) was 8.751 and the lower section (body) was 11.251 . Due to persistent baselining problems, we failed to measure the absolute values for evaporative water loss and $\mathrm{O}_{2}$ consumption. However, the output allowed us to record the temperature of panting onset using the sliding heating protocol (see below). For this analysis we used data from the upper section of the chamber (head compartment).

We performed the measurements using a sliding heating protocol. The respirometry chamber with the bird was placed inside a temperature-controlled box (35 1 MobiCool G35). We started the measurement with the flow rate through the chamber set to $3.31 \mathrm{~min}^{-1}$ for $15 \mathrm{~min}$ to enable a quick washout of the humidity accumulated in the chamber during the positioning of the bird. After the washout period, we decreased the flow to 0.661 $\min ^{-1}$ and started the heating of the chamber. Temperature in the temperature-controlled box was monitored continuously by a custom-made temperature logger (precision: $\pm 0.1^{\circ} \mathrm{C}$ ) attached inside the respirometry chamber. The starting temperature of the measurements was $31.0 \pm 3.4^{\circ} \mathrm{C}$ and progressively increased during the procedure at a rate of $\sim 0.3^{\circ} \mathrm{C} \mathrm{min}-1$. We continued the measurement for at least 5 min after noticing a sharp increase 
in excurrent air humidity in the upper chamber, which was a clear indication of the onset of panting. On average, the measurement of one bird took one hour and the average temperature at the end of the experiment was $39.3 \pm 1.6^{\circ} \mathrm{C}$. The bird was immediately released at the end of the trial, after being provided with water. We did not perform visual observations of bird behavior during these measurements.

\section{Behavioral Responses to Changes in Water Availability}

We experimentally examined the effect of water availability on the foraging and drinking behavior of staging birds at Midreshet BenGurion in 2018. We manipulated water availability at the same study site in which bird captures with mist netting took place (see CWL measurements). We created five drinking puddles of water using plastic sheets and fresh tap water. The puddles were placed in the shadow of large bushes 6-12 $\mathrm{m}$ from the closest mist net, with the exception of one puddle which was directly below a net. The plastic sheets were covered with soil before the puddles were filled to achieve a more natural setting. The puddles were filled and emptied alternately in a 5-day rhythm. The water regime change was always conducted at $10 \mathrm{PM}$. In total, water was provided on 13 days (two full 5-day periods and one truncated period at the end of the season), while the puddles were dry on 11 days (two full 5-day periods and one day before the start of the experiment). One additional artificial water body $(150 \times 70 \mathrm{~cm})$ was present at the site. It was built of concrete and had vertical walls. This reservoir was most likely not a suitable drinking place for birds, and none were ever observed to use it for drinking or bathing. However, we covered it with wire mesh $(0.5 \mathrm{~cm}$ mesh size) when the experimental ponds were dry and uncovered when water was provided at the experimental puddles.

We searched for Blackcaps and Lesser Whitethroats along a transect in the plantation. One observer walked the transect each day at 09:00, 11:00, 13:00, and 17:00 between September 5 and September 29 (excluding September 10 and September 16). The transect was approximately $1090 \mathrm{~m}$ long and its coverage took $45 \mathrm{~min}$. The observer scanned vegetational structures (bushes and trees) along a defined path for at least $2 \mathrm{~min}$ during each round. When a bird was encountered, we classified its behavior in one of the following four categories: (1) moving, (2) foraging, (3) resting, and (4) grooming. We observed each individual for 30-300 s and assigned a single behavior to each bird. When more than one behavior was expressed, we chose the behavior that lasted longer during the observation. Moving was defined as occasions when the bird was jumping or flying around. If during the movement the bird was seen pecking or eating at least once during the observation, we classified its behavior as foraging, because we assumed that movement could be related to food-searching. Resting was defined as cases when the bird just perched on a branch without undertaking any other activity. Grooming was defined as the bird taking care of its plumage during the observation time. It never occurred that a bird was foraging and resting/grooming during one observation sequence.
In addition to these observations, we set trail cameras (Cuddeback Long Range IR) at $80-130 \mathrm{~cm}$ distance from the edge of each artificial puddle. The cameras were attached to sticks $15-20 \mathrm{~cm}$ above the ground. They were set to take a picture and start a video recording for $30 \mathrm{~s}$ following every movement trigger and were active throughout the study period (including when the puddles were dry). We analyzed all pictures and videos and recorded all bird species present and the duration of their visit. Time and date were also recorded.

\section{DATA ANALYSIS}

\section{Field CWL Measurements}

In a first step of the analysis, we explored the factors that explained variation in CWL. We used a linear mixed-effects model with the surface-specific CWL $\left(\mathrm{g} \mathrm{m}^{-2} \mathrm{~h}^{-1}\right.$, measured with the vapometer) as a dependent variable. We used the average of the three lowest vapometer measurements as the response variable because the measured values decreased gradually from the first to the fifth measurement, reaching a plateau between the third and fifth. Since ambient temperature as well as air humidity influence CWL (Wolf and Walsberg, 1996; Tieleman and Williams, 2002; Gerson et al., 2014; Champagne et al., 2016), we included them as independent variables in the analysis, together with water in the puddles (no/yes), ordinal date, waiting time in the bag (CWL measurement time - extraction time from the net), and size-corrected body mass. Size-corrected body mass was calculated as: [(body mass/length of the folded wing) $\times$ (length of the folded wing)]. We used species as a random intercept to be able to detect within-species variation in CWL in relation to body mass. We eliminated non-significant predictor variables in a stepwise backward procedure, checking after every step that model deviance was not affected (Zuur et al., 2009). We examined all combinations of predictor variables used in the models for multicollinearity using scatterplot matrices and correlation coefficients (Pearson's $r$ ). All calculated $|r|$ - values were below 0.7 , which is considered to be a suitable indicator value above which multicollinearity severely distorts model estimations (Dormann et al., 2013). The model was tested for major violations of model assumptions by evaluating diagnostic plots (Zuur et al., 2009). After identifying the most influential parameter (which was $\mathrm{T}_{\mathrm{a}}$, see section "Results"), we tested for interspecific differences using ANCOVA, with surface-specific CWL as a dependent variable, $\mathrm{T}_{\mathrm{a}}$ as a continuous independent variable, species as a categorical independent factor, and the species $\times \mathrm{T}_{\mathrm{a}}$ interaction. The assumptions for ANCOVA were checked and met.

To determine the variability in total CWL in the three species, we modeled the slopes and intercepts for each species as obtained from the ANCOVA model. We obtained hourly ambient temperature data from the Israel Meteorology Service station located in Kibbutz Sde-Boker, approximately $3 \mathrm{~km}$ northeast of the Midreshet Ben-Gurion site. In both years September temperatures ranged between 14.0 and $36.5^{\circ} \mathrm{C}$, which overlaps with the range of temperatures at which bird CWL was measured. Using the equations describing the relationship between CWL 
and $\mathrm{T}_{\mathrm{a}}$, we calculated changes in total CWL $\left(\mathrm{g} \mathrm{H}_{2} \mathrm{O} \mathrm{h}^{-1}\right)$. Body surface area was calculated as $\mathrm{As}\left(\mathrm{cm}^{2}\right)=10$ body mass (g) ${ }^{0.667}$ (Walsberg and King, 1978). To simplify the approach, we assumed that CWL changes during the day only in relation to changes in $\mathrm{T}_{\mathrm{a}}$. We do realize that this approach is very simplistic, yet it provides information on the ecologically relevant species differences in CWL. Daily CWL was obtained by integrating the total CWL over a given day. Finally, we simulated changes in CWL using ambient temperature for days in September 2017 and 2018. Integrated total CWL was compared between species using a repeated ANOVA on ranks. We then compared CWL as a percentage of total body mass lost during the day in the three study species.

\section{Temperature of Panting Onset}

We used the absolute humidity values from the upper chamber as a proxy for RWL. We matched the temperature measurements in the temperature-controlled box with the humidity measurements from the upper chamber such that our dataset included data for every minute. We excluded the first $25 \mathrm{~min}$ (15 $\mathrm{min}$ washout +10 min equilibrium establishment) from the analysis. We used breakpoint analysis to identify the temperature at which a sharp increase in chamber humidity, an indication of panting, took place. We determined the breakpoint in the curve between the 26th minute of the measurement procedure and its end using the "segmented" function provided by the "segmented" package in R (Muggeo, 2009) and used this breakpoint as the temperature of panting onset for every individual. Sometimes the linear increase in RWL after the onset of panting became exponential toward the end of the measurements. We removed such points prior to the calculation of the segmented regression due to their high leverage on the estimate. Birds failing to show a clear breakpoint were not included in the analysis (12 out of $88 ; 3$ blackcaps, 4 lesser whitethroats, and 5 willow warblers). We compared the temperatures of panting onset between species using a one-way ANOVA after we ascertained that the normality assumption was met, as was the homogeneity of variances between the samples (Levene's Test from medians: $F_{2}, 73=0.473, p=0.625$ ). We used a Tukey HSD post hoc test to examine species-specific differences at a $95 \%$ confidence level.

\section{Behavioral Responses to Changes in Water Availability}

The probability of finding moving or foraging birds is consistently higher than for resting birds. To deal with this bias, we analyzed the relationship between daily captured and observed individuals in Blackcaps and Lesser Whitethroats. We ran a generalized linear model (GLM) with a Poisson error family, with the number of birds observed as a dependent variable, and the number of birds captured and the species as independent variables. The model fit was checked by visually inspecting diagnostic plots (Faraway, 2016). We cannot exclude that we observed some individuals multiple times, but we considered these observations as independent since we were not able to differentiate among individuals.
All analyses were performed with R 4.0.2 (R Core Team, 2020) within the RStudio IDE (version 1.4.1717).

\section{RESULTS}

\section{Field CWL Measurements}

We obtained $360 \mathrm{CWL}$ measurements from the three study species (Blackcap: $n=165$, Lesser Whitethroat: $n=89$, Willow Warbler: $n=108$ ). The results of the mixed-effects model are shown in Table 2 . The variables retained in the model were $\mathrm{T}_{\mathrm{a}}, \mathrm{AH}$, date, water in the puddles, and size-corrected body mass. The effect sizes of $\mathrm{AH}$ and date were small and were considered irrelevant, and in addition, the low $t$-value $(<2)$ for $\mathrm{AH}$ indicated that this effect was not significant. $\mathrm{T}_{\mathrm{a}}$ had a positive effect on surface-specific CWL, while the availability of water and size-corrected body mass were negatively correlated to surface-specific CWL (Table 2 and Figure 2). The ANCOVA confirmed the positive effect of $\mathrm{T}_{\mathrm{a}}$ on surface-specific CWL (Table 3). There were also significant differences between species, with Blackcaps having higher surface-specific CWL than Lesser Whitethroats and Willow Warblers (Table 3). This was mostly due to higher values at low temperatures, as confirmed by the significant difference in the slope of surface-specific CWL in relation to $\mathrm{T}_{\mathrm{a}}$ (Table 3 and Figure 3 ).

Daily absolute CWL simulated by our model equaled: $2.025 \pm 0.085 \mathrm{~g} \mathrm{H}_{2} \mathrm{O}$ day $^{-1}$ in Blackcaps, $1.520 \pm 0.083 \mathrm{~g}$ $\mathrm{H}_{2} \mathrm{O}$ day $^{-1}$ in Lesser Whitethroats, and $1.230 \pm 0.072 \mathrm{~g} \mathrm{H}_{2} \mathrm{O}$ day $^{-1}$ in Willow Warblers. Expressed as a percentage of body mass, Blackcaps would lose $11.31 \pm 0.47 \%$, Lesser Whitethroats $11.96 \pm 0.65 \%$, and Willow Warblers $13.71 \pm 0.80 \%$ of body mass daily by cutaneous evaporation only (Figure 4). These differences among species were statistically significant ( $\mathrm{rm}$ ANOVA on ranks, $\left.\chi^{2}=120, d f=2, p<0.001\right)$.

\section{Temperature of Panting Onset}

We estimated the temperature of panting onset of 76 birds (Blackcap: $n=30$, Lesser Whitethroat: $n=25$, Willow Warbler: $n=21)$. It differed significantly between the three study

TABLE 2 | Results of a linear mixed-effects model with surface-specific CWL as dependent variable.

\begin{tabular}{lccc}
\hline Fixed effects: & & & \\
\hline & Estimate & Std. error & $\boldsymbol{t}$-value \\
\hline Intercept & -4.066 & 3.888 & -1.046 \\
$\mathrm{~T}_{\mathrm{a}}$ & 0.416 & 0.023 & 17.844 \\
Ambient humidity & 0.046 & 0.042 & 1.106 \\
Date & 0.028 & 0.013 & 2.123 \\
Water (yes) & -0.487 & 0.188 & -2.590 \\
Size-corrected body mass & -0.135 & 0.044 & -3.098 \\
\hline Random effects: & & & \\
\hline & & Variance & Std. dev. \\
\hline Species & Intercept & 0.752 & 0.867 \\
Residual & & 2.964 & 1.722 \\
\hline
\end{tabular}

$N=360$ observations of three species. 


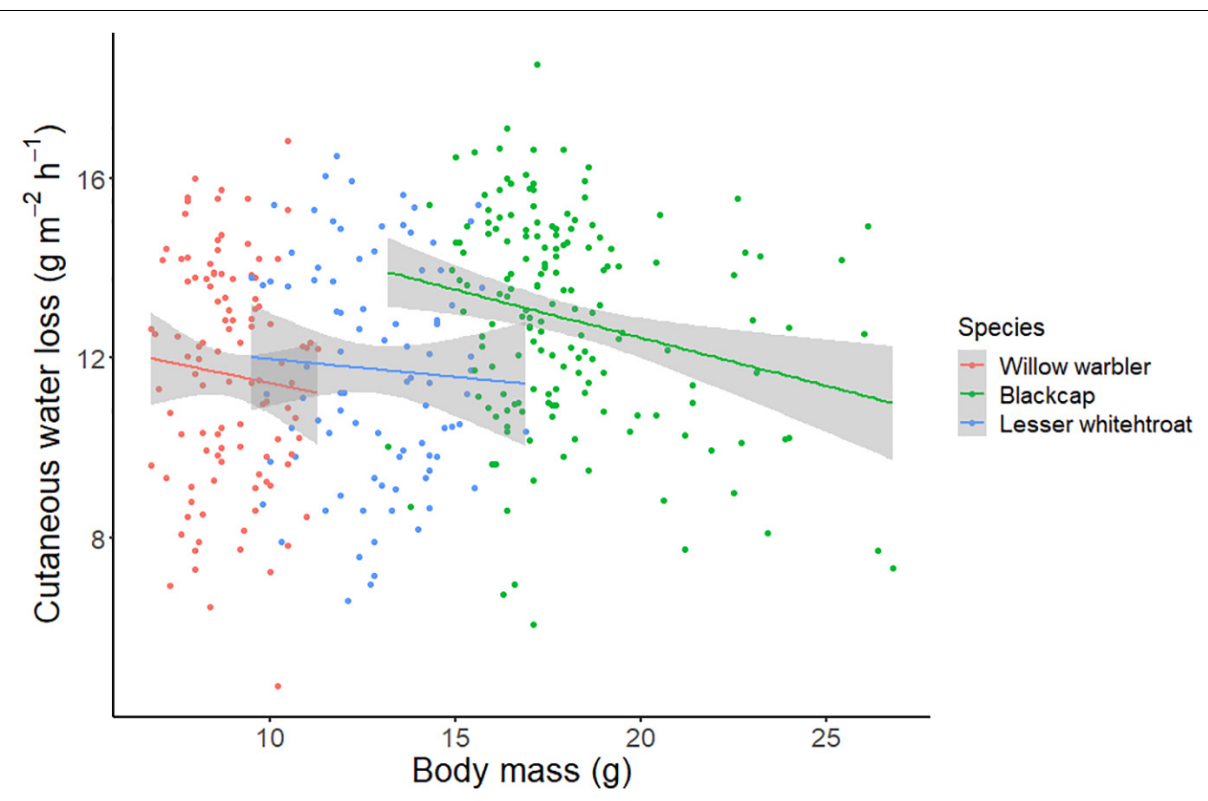

FIGURE 2 | Relationship between body mass and surface-specific CWL in the three study species. In all three species, there is a negative relationship between body mass and CWL.

species (one-way ANOVA: $F_{2,73}=5.137, p=0.008$, Figure 5). Blackcaps started panting at a lower temperature (mean \pm 1 SD: $36.5^{\circ} \mathrm{C} \pm 1.6^{\circ} \mathrm{C}$ ) than Lesser Whitethroats $\left(37.6^{\circ} \mathrm{C} \pm 1.5^{\circ} \mathrm{C}\right.$; Tukey HSD post hoc Test: adj. $p=0.048)$ and Willow Warblers $\left(37.9^{\circ} \mathrm{C} \pm 1.8^{\circ} \mathrm{C}\right.$; Tukey HSD post hoc Test: adj. $\left.p=0.020\right)$. Lesser Whitethroats and Willow Warblers did not differ in their temperature of panting onset (adj. $p=0.804)$.

\section{Behavioral Responses to Water}

During autumn 2018 we captured 181 Blackcaps, 89 Lesser Whitethroats and 133 Willow Warblers. During 90 transects (45 min each, totaling $67.5 \mathrm{~h}$ ) we observed 26 Blackcaps and 83 Lesser Whitethroats. The number of birds observed increased on average by $0.12 \pm 0.04$ with every captured bird (GLM: $z=3.02, p=0.003$ ), and the slope of the increase was not

TABLE 3 | Results of the ANCOVA with surface-specific CWL as a dependent variable.

\section{Coefficients}

\begin{tabular}{lrcrr}
\hline & Estimate & Std. error & t value & \multicolumn{1}{c}{$\boldsymbol{p}$} \\
\hline Intercept & 0.637 & 0.998 & 0.638 & 0.524 \\
$\mathrm{~T}_{\mathrm{a}}$ & 0.461 & 0.041 & 11.162 & $<0.001$ \\
Species (Blackcap) & 3.386 & 1.310 & 2.585 & 0.010 \\
Species (L. Whitethr.) & 0.726 & 1.472 & 0.493 & 0.622 \\
$\mathrm{~T}_{\mathrm{a}} \times$ Species (Blackcap) & -0.119 & 0.052 & -2.268 & 0.024 \\
$\mathrm{~T}_{\mathrm{a}} \times$ species (L. Whitethr.) & -0.041 & 0.060 & -0.680 & 0.497
\end{tabular}

Residual standard error was 1.757 on 356 degrees of freedom.

Adj. $R^{2}=0.505, F_{5,356}=74.68, p<0.001$.

In this table, the Willow Warbler is used as a reference category for the effects of species. different between species (GLM, interaction term species $\times$ birds captured: estimate $=0.01 \pm 0.06, z=0.14, p=0.888)$. Significantly more Lesser Whitethroats were observed along the transects than Blackcaps (GLM, main effect of species: estimate $=1.69 \pm 0.51$, $z=3.29, p=0.001)$.

Most birds were observed moving or foraging in the vegetation (Blackcap: 92.6\%; Lesser Whitethroat: 95.1\%). The remaining birds were resting (Figure 6). The proportion of foraging and moving birds did not differ significantly between days with water availability and days with no water (Chi-square test: $\chi^{2}=0.050$, $d f=1, p=0.822$ ). Comfort behavior and resting were excluded from the test due to small sample sizes or lack thereof.

In 2018 we recorded 143 individuals from 13 bird species at the artificial puddles. The most abundant were resident bird species, while only a few migratory birds occurred at the ponds for drinking. Of our focal species, four Blackcaps, nine Lesser Whitethroats and four Willow Warblers were observed at the puddles. Mean duration of stay at the puddle did not differ among the three species (one-way ANOVA: $F_{2,13}=0.342$, $p=0.717$, Table 4).

\section{DISCUSSION}

We found partial support to our prediction that our three study species would have different adaptations to arid conditions. Blackcaps had slightly higher surface-specific CWL than Lesser Whitethroats and Willow Warblers, but this difference was mostly due to higher CWL at $\mathrm{T}_{\mathrm{a}}$ 's well below $\mathrm{T}_{\mathrm{b}}$. When extrapolated over the whole body surface, the species with the highest overall CWL were also the ones showing higher activity levels, which is against our expectations. However, as predicted, the onset of panting occurred at lower $\mathrm{T}_{\mathrm{a}}$ in Blackcaps compared 


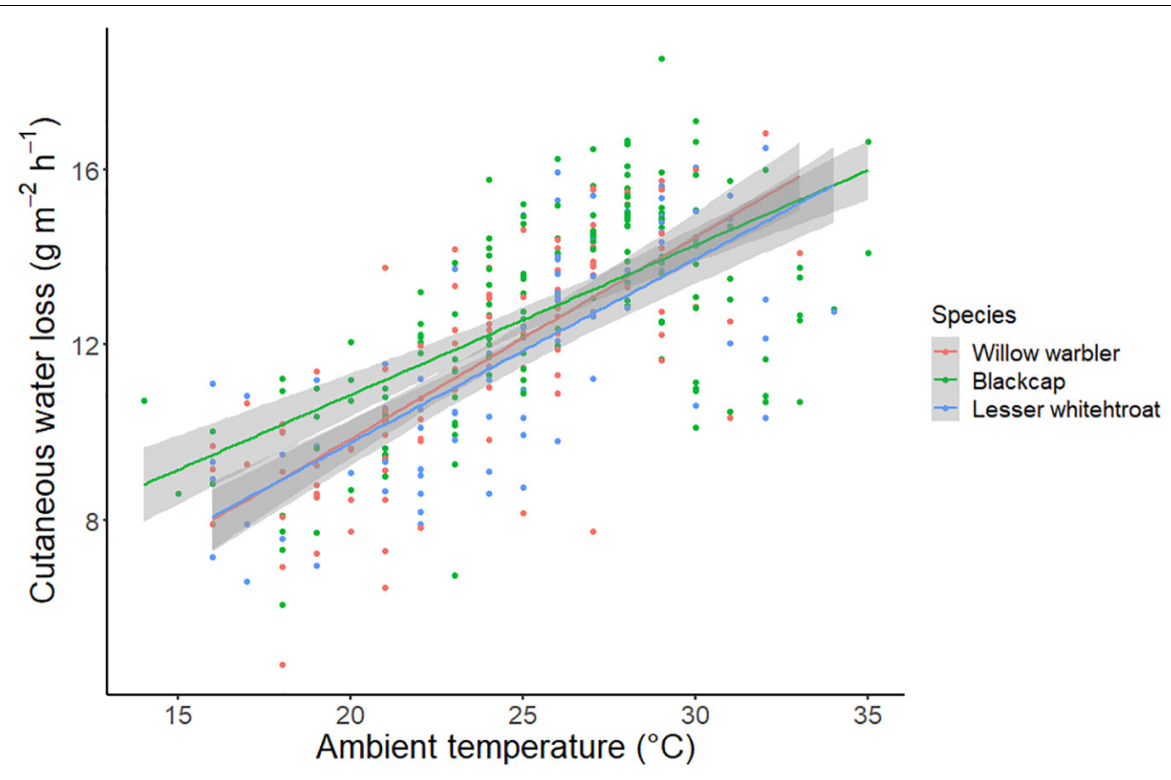

FIGURE 3 | Relationship between $\mathrm{T}_{\mathrm{a}}$ and surface-specific CWL in the three study species. Blackcaps (green) had significantly higher overall CWL than the other two species, as a result of higher values at low $T_{a}$.

to the other two species. The availability of water did not seem to influence the birds' activity. Taken together, these results do not support the hypothesis that the activity of birds at a stopover site would be associated with the risk of dehydration. However, physiological constraints related to water can help explain the birds' behavior.

The measured maximum CWL ranged between 34 and $36 \mathrm{mg}$ $\mathrm{H}_{2} \mathrm{O} \mathrm{cm} \mathrm{cm}^{-2}$ day $^{-1}$, and were within the range of 12 temperate

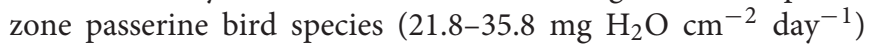

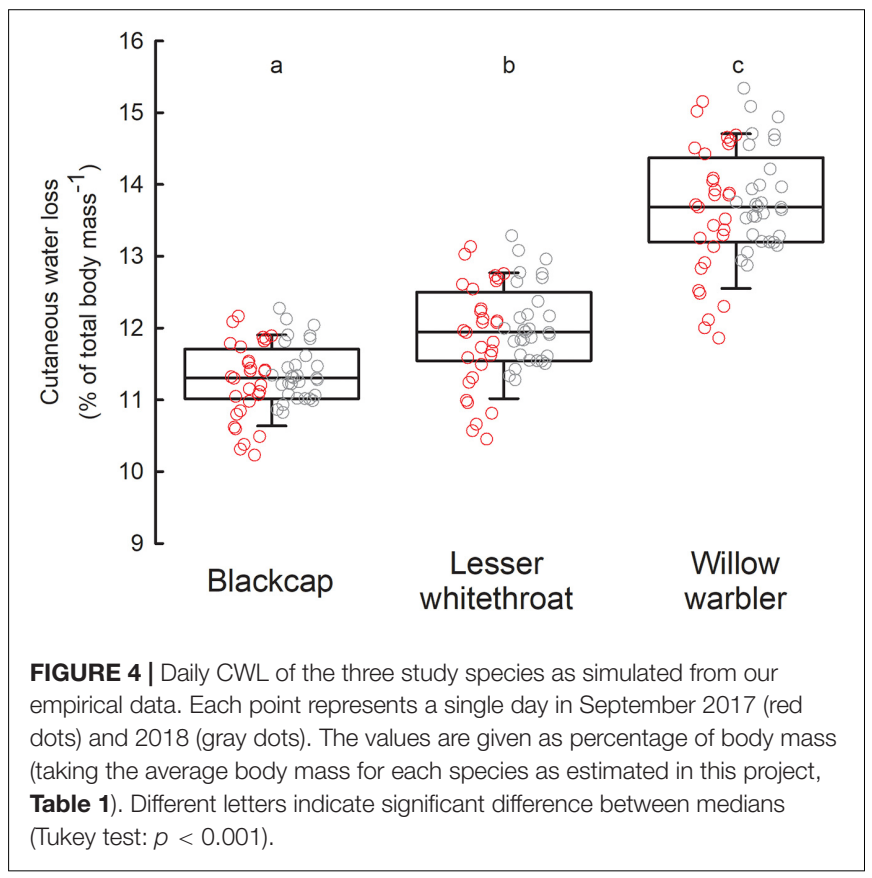

measured in dry conditions (Ro and Williams, 2010). Our simulated data show that this represents a daily CWL of $11-13 \%$ of the total body mass of the focal species. Though we have no data on RWL, we can assume that this would have similar values, because in passerines, at $\mathrm{T}_{\mathrm{a}}$ 's below the panting threshold, there is an approximate 50:50 ratio of CWL and RWL (Tieleman and Williams, 2002; Muñoz-Garcia and Williams, 2005). Therefore, assuming that a bird would sit completely still in a shaded area during a whole day, its TEWL would be in the range of $20-26 \%$ of body mass, depending on the species. This by far exceeds the $11 \%$ dehydration threshold for the maintenance of coordination in small passerines (Wolf and Walsberg, 1996). In the bird species measured so far, total body water in healthy individuals is about $60-65 \%$ of body mass (Hughes et al., 1987; Ellis and Jehl, 1991; Speakman, 1997). Our predicted water loss is therefore in the range of $31-43 \%$ of the total body water. This implies that birds must replenish their water reserves to avoid death by dehydration. Foraging activity might expose the animals to higher $\mathrm{T}_{\mathrm{a}}$ and, possibly, direct sunlight. This, together with an increase in metabolic heat production due to muscular work would sharpen the need for evaporative cooling and result in even higher water loss.

While part of the lost body water might be produced metabolically (Morrison, 1953), the main avenue for obtaining additional water for most bird species is food, especially when no drinking water is available. Some species are even known not to drink when surface water is available (Smit et al., 2016; Czenze et al., 2020), and for these species it is imperative to obtain their water through foraging. Despite the percentage of active birds observed was similar for Lesser Whitethroats and Blackcaps, the proportion of observed to trapped birds was much higher for Lesser Whitethroats. This suggests that inactive Blackcaps were likely underrepresented in our observation study, 


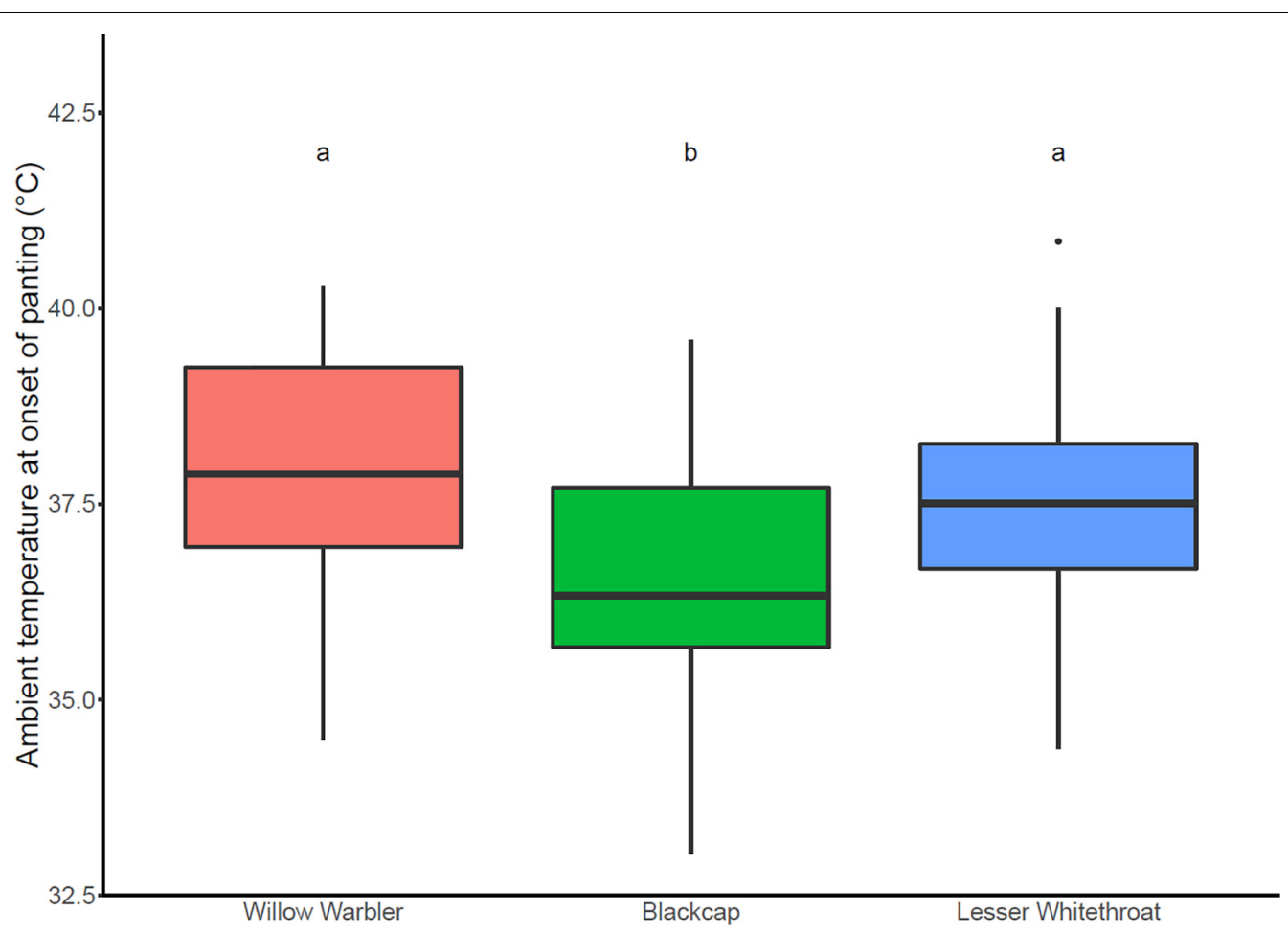

FIGURE 5 | Temperature of panting onset in the three study species. Species marked with the same letters (a, b) were not significantly different. Willow Warbler (orange): $n=21$; Blackcap (green): $n=30$; Lesser Whitethroat (blue): $n=25$.

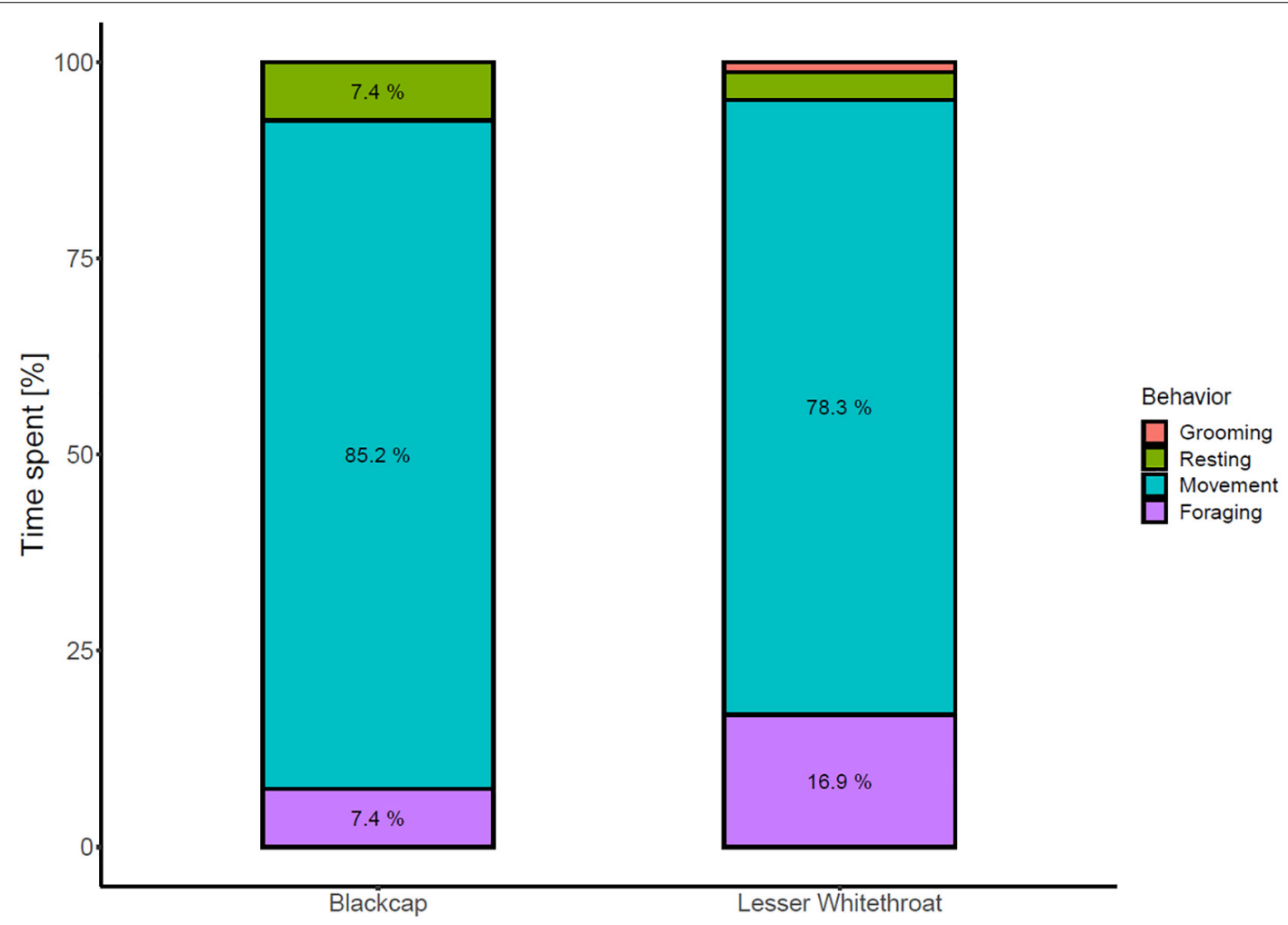

FIGURE 6 | Behavior of Blackcaps and Lesser Whitethroats at Midreshet Ben-Gurion in September 2018. Behavioral observations were not performed on Willow Warblers. Blackcap: $n=26$; Lesser Whitethroat: $n=83$. In Lesser Whitethroats, values for resting and grooming behavior were 3.6 and $1.2 \%$, respectively. 
TABLE 4 | Number of birds recorded and mean duration of stay $( \pm S D$, only for species with $N>3$ ) at the artificial puddles during the study in 2018.

\begin{tabular}{|c|c|c|c|c|}
\hline \multirow[t]{2}{*}{ Species } & \multicolumn{2}{|c|}{ Water } & \multirow{2}{*}{$\begin{array}{c}\text { Total } \\
\text { captures }\end{array}$} & \multirow{2}{*}{$\begin{array}{c}\text { Mean duration } \\
\text { (sec) }\end{array}$} \\
\hline & Yes & No & & \\
\hline $\begin{array}{l}\text { European Turtle Dove Streptopelia } \\
\text { turtur }\end{array}$ & 2 & 2 & 1 & \\
\hline Red-backed Shrike Lanius collurio & 1 & 0 & 18 & \\
\hline $\begin{array}{l}\text { White-spectacled Bulbul } \\
\text { Pycnonotus xanthopygos* }\end{array}$ & 51 & 0 & 13 & $24.4 \pm 7.9$ \\
\hline $\begin{array}{l}\text { Willow Warbler Phylloscopus } \\
\text { trochilus }\end{array}$ & 4 & 0 & 122 & $12.3 \pm 10.9$ \\
\hline Blackcap Sylvia atricapilla & 4 & 0 & 143 & $18.5 \pm 8.6$ \\
\hline $\begin{array}{l}\text { Common Whitethroat Sylvia } \\
\text { communis }\end{array}$ & 5 & 0 & 10 & $21.0 \pm 6.7$ \\
\hline $\begin{array}{l}\text { Eastern Orphean Warbler Sylvia } \\
\text { crassirostris }\end{array}$ & 1 & 0 & 12 & \\
\hline $\begin{array}{l}\text { Lesser Whitethroat Sylvia } \\
\text { curruca }\end{array}$ & 9 & 0 & 89 & $15.3 \pm 11.4$ \\
\hline $\begin{array}{l}\text { Arabian Babbler Turdoides } \\
\text { squamiceps }^{\star}\end{array}$ & 14 & 1 & 0 & $16.7 \pm 9.6$ \\
\hline $\begin{array}{l}\text { Spotted Flycatcher Muscicapa } \\
\text { striata }\end{array}$ & 1 & 0 & 11 & \\
\hline $\begin{array}{l}\text { Rufous-tailed Scrub Robin } \\
\text { Cercotrichas galactotes }\end{array}$ & 30 & 17 & 3 & $22.1 \pm 9.5$ \\
\hline Ortolan Bunting Emberiza hortulana & 1 & 0 & 1 & \\
\hline
\end{tabular}

Target species are outlined in bold and resident species are marked with *.

The total number of captures refers to the period 05.09.2018-27.09.2018 and is given as a proxy for the abundance of the species.

However, species of large size might be underrepresented because mist nets are not designed for capture of these species.

because of lower detectability. This suggests that, overall, Lesser Whitethroats are more active than Blackcaps, which can be associated with the higher percentage of body water that they lose through CWL. Unfortunately, we have no data on the activity of Willow Warblers, but previous studies conducted in the Sahara Desert showed that they are also actively foraging during stopovers (Jenni-Eiermann et al., 2011; Maggini et al., 2015). Intriguingly, these differences do not seem to have arisen by different adaptations of the skin membranes among species (as shown e.g., in larks and sparrows, Tieleman and Williams, 2002; Muñoz-Garcia et al., 2012), since the surface-specific rate of CWL was fairly comparable among species. It is possible that a difference would be observable during spring migration, since Blackcaps spend the winter in more mesic habitats than Lesser Whitethroats (Snow et al., 1997; Shirihai et al., 2001) and their skin membranes might be accordingly flexibly adjusted to the arid conditions at the wintering grounds (Muñoz-Garcia et al., 2008). The higher percentage of water loss in the Willow Warbler could be an indication of higher evaporative cooling efficiency (the rate of heat loss over heat production). As a result, this species may afford higher activity and exposure to higher $\mathrm{T}_{\mathrm{a}}$, provided that the amount of water lost does not exceed a threshold above which dehydration would pose a death threat (Albright et al., 2017; Conradie et al., 2020).

The main behavioral and physiological indication of the risk of dehydration at high ambient temperatures is the onset of panting
(Pattinson et al., 2020). The results of this study confirmed the prediction that Blackcaps have a lower temperature of panting onset than Willow Warblers and Lesser Whitethroats. The mean values we measured in the three species (Blackcap: $36.5^{\circ} \mathrm{C}$, Lesser Whitethroat: $37.6^{\circ} \mathrm{C}$, Willow Warbler: $37.9^{\circ} \mathrm{C}$ ) were in the range of temperatures $\left(31.3^{\circ} \mathrm{C}-46^{\circ} \mathrm{C}\right.$, mean: $\left.39.3^{\circ} \mathrm{C}\right)$ at which $50 \%$ of the individuals from 33 different Kalahari Desert bird species were observed to begin panting (Smit et al., 2016). This result provides a promising avenue to explain the evolution of the different use of stopover sites in migratory species. It also indicates that behavioral characteristics of response to heat could be relevant for sites outside the desert as well. It has to be noted that larger species usually initiate heat dissipation behaviors (e.g., panting and wing drooping) at lower temperatures than smaller species due to their smaller surface to volume-ratio (Weathers, 1981; Smit et al., 2016; Pattinson et al., 2020). This could be an explanation for the observation in our study. In addition, different adaptations to optimize heat loss in arid conditions, such as the ability to tolerate high body temperatures during facultative hyperthermia (Tieleman and Williams, 1999; Smit et al., 2013, 2016; Nilsson et al., 2016), the dependence on wing-drooping as alternative heat dissipation behavior (Smit et al., 2016; Wojciechowski et al., 2021) or the reduction of metabolic rate (Williams and Tieleman, 2005; Wojciechowski et al., 2021) may also influence the temperature of panting onset. These factors clearly indicate new avenues for further research investigating the response of different species to dehydrating conditions.

Interestingly, surface-specific CWL was negatively correlated with body mass in all three species studied. Since body mass is largely affected by fat stores in migratory birds, this provides an indication that subcutaneous fat may be directly or indirectly related to cutaneous evaporation. However, the mechanistic processes involved are still unknown yet. Surface-specific CWL values were also lower when water was available in the puddles. This difference was relatively small $\left(\sim 0.5 \mathrm{~g} \mathrm{~m}^{-2} \mathrm{~h}^{-1}\right)$ but statistically significant. This may suggest that birds with slightly lower CWL were more likely to be captured on days where water was available. This is somewhat counterintuitive, because we would have expected birds with higher water losses to be more motivated to replenish their water content by drinking or foraging more actively. A possible explanation might include a combination of the effects of body condition (heavier birds the ones with lower CWL - could be the ones that are more active when water is available) and diet. Birds that consume drier food are more affected by the lack of water (Mizrahy et al., 2011). These birds might be taking advantage of the availability of surface water.

Our study integrates physiological and behavioral data for better explaining differences in stopover ecology among three migratory species that were about to cross a wide ecological barrier, the Sahara Desert, on their way from the temperate breeding areas to their sub-Saharan over-wintering grounds. Our comparison between captured and observed birds showed that Lesser Whitethroats are observed far more often than Blackcaps at the study site, despite the lower number of captures. This confirms that Blackcaps spend more time resting in deep 
foliage than Lesser Whitethroats at this autumn stopover site in Israel. Despite simulating Sapir et al.'s (2004) study closely, our data do not suggest that the availability of drinking water would affect the behavior of Blackcaps by inducing increased foraging as they were only observed drinking at the artificial puddles rarely, and proportionally less than Lesser Whitethroats. However, Midreshet Ben-Gurion was recently found to act as an unordinary stopover site. While many passerines during autumn migration are attracted to it, most of them abandon it during their first morning (Domer et al., 2018). Given this information, the behavioral part of this study should be treated accordingly, as birds will actively forage only a few days after landing once they fully restored their digestive capacity (Gannes, 2002; McWilliams and Karasov, 2005).

The results of this study suggest that evaporative water loss provides an important physiological background that might have played a crucial role in the evolution of different desert-crossing strategies in small trans-Saharan migrants. While some species rely on en route refueling to cross the Sahara, others gain the necessary amounts of fat prior to the desert crossing (JenniEiermann et al., 2011; Arizaga et al., 2013; Hama et al., 2013). Both strategies are successful and enable billions of birds to cross this large ecological barrier twice a year (Moreau, 1972; Hahn et al., 2009). However, the populations of many migratory bird species of the Old World are declining, and especially transSaharan migrants do so to a greater extent than resident or short-distance migrants (Vickery et al., 2014). Climate change leads to more arid conditions for the whole African continent (Nicholson et al., 2018), potentially imposing constraints on birds that use both refueling strategies before, during and after crossing the desert. While species which rely on pre-departure fattening might be confronted with the energetic challenge of carrying even higher fat loads in order to be able to cross an enlarged desert barrier, species which refuel en route might experience more difficulties to find suitable oases for efficient fat accumulation.

This study provides a first step toward identifying potential physiological mechanisms that constrain the birds' behavior during a challenging phase of their migration. However, many open questions on the physiological mechanisms involved in the evolution of different refueling strategies and their speciesspecific consequences for the entire migration process remain to be addressed. We argue that explaining the behavior of migratory birds through physiological adaptations should be addressed through a mechanistic approach by applying comparative and experimental studies.

\section{REFERENCES}

Abáigar, T., Cano, M., and Ensenyat, C. (2018). Time allocation and patterns of activity of the dorcas gazelle (Gazella dorcas) in a sahelian habitat. Mamm. Res. 63, 73-82. doi: 10.1007/s13364-017-0334-0

Adamík, P., Emmenegger, T., Briedis, M., Gustafsson, L., Henshaw, I., Krist, M., et al. (2016). Barrier crossing in small avian migrants: individual tracking reveals prolonged nocturnal flights into the day as a common migratory strategy. Sci. Rep. 6:21560. doi: 10.1038/srep21560

Albright, T. P., Mutiibwa, D., Gerson, A. R., Smith, E. K., Talbot, W. A., O’Neill, J. J., et al. (2017). Mapping evaporative water loss in desert passerines reveals

\section{DATA AVAILABILITY STATEMENT}

The datasets presented in this study can be found in online repositories. The names of the repository/repositories and accession number(s) can be found below: https://phaidra. vetmeduni.ac.at/o:669.

\section{ETHICS STATEMENT}

The animal study was reviewed and approved by Israel Nature and National Parks Authority.

\section{AUTHOR CONTRIBUTIONS}

IM, ES, and NS conceived the study. BP, BW, DB, and YZ performed fieldwork. BP, BW, MW, and IM performed data analysis. BP, BW, AD, MW, and IM wrote the manuscript. YZ, ES, and NS provided logistical support. All authors read and approved the final version of the manuscript.

\section{FUNDING}

This study was supported by a start-up grant (Profillinien) of the University of Veterinary Medicine Vienna to IM. The University of Vienna supported BP with a Grant Abroad (KWA) as well as a Needs-based Scholarship (Förderstipendium), and BW with a Needs-based Scholarship (Förderstipendium). NS was supported by the Israel Science Foundation (Grant 702/17), and MW was supported by the Polish National Science Centre (Grant 2017/25/B/NZ8/00541).

\section{ACKNOWLEDGMENTS}

We thank Ofer Ovadia for allowing us to work at the Ben-Gurion University of the Negev. We also thank Finja Strehmann, Sarah Degenhart, and Ron Efrat for their help during fieldwork. Benjamin Seaman proofread a previous version of the manuscript. Yosef Kiat from the Israeli Bird Ringing Center (IBRC), Israel Ornithological Center of the Society for the Protection of Nature in Israel provided unpublished data of ring recoveries, the Israel Meteorology Service provided data used in this work, and Christian Schulze provided the camera traps.

an expanding threat of lethal dehydration. Proc. Natl. Acad. Sci. U.S.A. 114, 2283-2288. doi: 10.1073/pnas.1613625114

Arizaga, J., Maggini, I., Hama, F., Crespo, A., and Gargallo, G. (2013). Site- and species-specific fuel load of European-Afrotropical passerines on arrival at three oases of southeast Morocco during spring migration. Bird Study 60, 11-21. doi: 10.1080/00063657.2012.735222

Bairlein, F. (1988). How do migratory songbirds cross the Sahara? Trends Ecol. Evol. 3, 191-194. doi: 10.1016/0169-5347(88)90005-5

Bairlein, F. (1995). European-African Songbird Migration Network. Manual of Field Methods. Revised edition. Germany: European Science Foundation.

Baker, K. (2010). Warblers of Europe, Asia and North Africa. London: A\&C Black. 
Biebach, H. (1985). Sahara stopover in migratory flycatchers: fat and food affect the time program. Experientia 41, 695-697. doi: 10.1007/BF02007727

Calder, W. A., and King, J. R. (1974). "Thermal and caloric relations of birds," in Avian biology, eds D. S. Farner and J. R. King (New York: Academic Press), 259-413.

Champagne, A. M., Allen, H. C., Bautista-Jimenez, R. C., and Williams, J. B. (2016). Organization of lipids in avian stratum corneum: Changes with temperature and hydration. Chem. Phys. Lipids 195, 47-57. doi: 10.1016/j.chemphyslip.2015. 12.001

Champagne, A. M., Munoz-Garcia, A., Shtayyeh, T., Tieleman, B. I., Hegemann, A., Clement, M. E., et al. (2012). Lipid composition of the stratum corneum and cutaneous water loss in birds along an aridity gradient. J. Exp. Biol. 215, 4299-4307. doi: 10.1242/jeb.077016

Conradie, S. R., Woodborne, S. M., Wolf, B. O., Pessato, A., Mariette, M. M., and McKechnie, A. E. (2020). Avian mortality risk during heat waves will increase greatly in arid Australia during the 21st century. Conserv. Physiol. 8:coaa048. doi: 10.1093/conphys/coaa048

Czenze, Z. J., Kemp, R., van Jaarsveld, B., Freeman, M. T., Smit, B., Wolf, B. O., et al. (2020). Regularly drinking desert birds have greater evaporative cooling capacity and higher heat tolerance limits than non-drinking species. Funct. Ecol. 34, 1589-1600. doi: 10.1111/1365-2435.13573

Dawson, W. R. (1982). Evaporative losses of water by birds. Comp. Biochem. Physiol. A. 71, 495-509. doi: 10.1016/0300-9629(82)90198-0

Domer, A., Ovadia, O., and Shochat, E. (2018). Energy for the road: Influence of carbohydrate and water availability on fueling processes in autumn-migrating passerines. Auk 135, 534-546. doi: 10.1642/AUK-17-228.1

Donald, J., and Pannabecker, T. L. (2015). "Osmoregulation in Desert-Adapted Mammals," in Sodium and Water Homeostasis: Comparative, Evolutionary and Genetic Models Physiology in Health and Disease, eds K. A. Hyndman and T. L. Pannabecker (New York, NY: Springer), 191-211. doi: 10.1007/978-1-49393213-9_10

Dormann, C. F., Elith, J., Bacher, S., Buchmann, C., Carl, G., Carré, G., et al. (2013). Collinearity: a review of methods to deal with it and a simulation study evaluating their performance. Ecography 36, 27-46. doi: 10.1111/j.1600-0587. 2012.07348.x

du Plessis, J., Stefaniak, A., Eloff, F., John, S., Agner, T., Chou, T.-C., et al. (2013). International guidelines for the in vivo assessment of skin properties in nonclinical settings: Part 2. transepidermal water loss and skin hydration. Skin Res. Technol. 19, 265-278. doi: 10.1111/srt.12037

Ellis, H. I., and Jehl, J. R. (1991). Total body water and body composition in phalaropes and other birds. Physiol. Zool. 64, 973-984. doi: 10.1086/physzool. 64.4.30157952

Faraway, J. J. (2016). Extending the Linear Model with R: Generalized Linear, Mixed Effects and Nonparametric Regression Models, Second Edition. Florida: CRC Press.

Gannes, L. Z. (2002). Mass change pattern of blackcaps refueling during spring migration: evidence for physiological limitations to food assimilation. Condor 104, 231-239. doi: 10.1650/0010-5422(2002)104[0231:mcpobr]2.0.co;2

Gerson, A. R., Smith, E. K., Smit, B., McKechnie, A. E., and Wolf, B. O. (2014). The Impact of Humidity on Evaporative Cooling in Small Desert Birds Exposed to High Air Temperatures. Physiol. Biochem. Zool. 87, 782-795. doi: 10.1086/ 678956

Goldreich, Y. (2012). The Climate of Israel: Observation, Research and Application. Netherland: Springer Science \& Business Media.

Hahn, S., Bauer, S., and Liechti, F. (2009). The natural link between Europe and Africa - 2.1 billion birds on migration. Oikos 118, 624-626. doi: 10.1111/j.16000706.2008.17309.x

Hama, F., Gargallo, G., Benhoussa, A., Zerdouk, S., and Rguibi Idrissi, H. (2013). Autumn body condition of Palaearctic trans-Saharan migrant passerines at an oasis in southeast Morocco. Ring Migr. 28, 77-84. doi: 10.1080/03078698.2013. 869886

Haran, R., and Izhaki, I. (2013). Two major autumn migration strategies of Willow Warblers Phylloscopus trochilus in the eastern Mediterranean Basin. Ring Migr. 28, 98-105. doi: 10.1080/03078698.2013.869896

Haugen, M., Williams, J. B., Wertz, P., and Tieleman, B. I. (2003). Lipids of the stratum corneum vary with cutaneous water loss among larks along a temperature-moisture gradient. Physiol. Biochem. Zool. 76, 907-917. doi: 10. $1086 / 380213$
Haugen, M. J. (2003). Phenotypic flexibility in cutaneous water loss and lipids of the stratum corneum. J. Exp. Biol. 206, 3581-3588. doi: 10.1242/jeb.0 0596

Hughes, M. R., Roberts, J. R., and Thomas, B. R. (1987). Total body water and Its turnover in free-living nestling glaucous-winged gulls with a comparison of body water and water flux in avian species with and without salt glands. Physiol. Zool. 60, 481-491. doi: 10.1086/physzool.60.4.30157910

Izhaki, I., and Maitav, A. (1998). Blackaps Sylvia atricapilla stopping over at the desert edge; physiological state and flight-range estimates. IBIS 140, 223-233. doi: 10.1111/j.1474-919X.1998.tb04383.x

Jenni-Eiermann, S., Almasi, B., Maggini, I., Salewski, V., Bruderer, B., Liechti, F., et al. (2011). Numbers, foraging and refuelling of passerine migrants at a stopover site in the western Sahara: diverse strategies to cross a desert. J. Ornithol. 152, 113-128. doi: 10.1007/s10336-010-0572-2

Jiguet, F., Burgess, M., Thorup, K., Conway, G., Arroyo Matos, J. L., Barber, L., et al. (2019). Desert crossing strategies of migrant songbirds vary between and within species. Sci. Rep. 9:20248. doi: 10.1038/s41598-019-56677-4

Kaiser, A. (1993). A new multi-category classification of subcutaneous fat deposits of songbirds. J. Field Ornithol. 64, 246-255.

King, J. R., and Farner, D. S. (1961). "Energy metabolism, thermoregulation and body temperature," in Biology and comparative physiology of birds, ed. A. J. Marshall (Florida: CRC Press), 215-288. doi: 10.1016/b978-1-4832-3143-3. 50014-9

Louw, G. (1993). Physiological animal ecology. J. New Jersey, NJ: Wiley.

Maggini, I., Hama, F., Robson, D., Rguibi Idrissi, H., Bairlein, F., and Gargallo, G. (2015). Foraging behavior of three species of songbirds during stopover in southeastern Morocco during spring migration. J. Field Ornithol. 86, 266-276. doi: $10.1111 /$ jofo. 12115

Malmiga, G., Tarka, M., Alerstam, T., Hansson, B., and Hasselquist, D. (2021). Individual and sex-related patterns of prolonged flights during both day and night by great reed warblers crossing the Mediterranean Sea and Sahara Desert. J. Avian. Biol. 52:e02549. doi: 10.1111/jav.02549

McKechnie, A. E., and Wolf, B. O. (2004). Partitioning of evaporative water loss in white-winged doves: plasticity in response to short-term thermal acclimation. J. Exp. Biol. 207, 203-210. doi: 10.1242/jeb.00757

McKechnie, A. E., and Wolf, B. O. (2010). Climate change increases the likelihood of catastrophic avian mortality events during extreme heat waves. Biol. Lett. 6, 253-256. doi: 10.1098/rsbl.2009.0702

McKechnie, A. E., and Wolf, B. O. (2019). The physiology of heat tolerance in small endotherms. Physiology 34, 302-313. doi: 10.1152/physiol.00011.2019

McWilliams, S. R., and Karasov, W. H. (2005). "Migration takes guts," in Birds of two worlds: the ecology and evolution of migration, ed. P. P. Marra (Washington, DC: Smithsonian Institution Press), 67-78.

Mizrahy, O., Bauchinger, U., Aamidor, S. E., McWilliams, S. R., and Pinshow, B. (2011). Availability of water affects renewal of tissues in migratory blackcaps during stopover. Integr. Comp. Biol. 51, 374-384. doi: 10.1093/icb/icr005

Moreau, R. E. (1972). The Palaearctic-African Bird Migration Systems. London: Academic Press.

Morrison, S. D. (1953). A method for the calculation of metabolic water. J. Physiol. 122, 399-402. doi: 10.1113/jphysiol.1953.sp005009

Muggeo, V. M. (2009). Segmented: an R package to fit regression models with broken-line relationships. R. News 8, 20-25.

Muñoz-Garcia, A., Ro, J., Reichard, J. D., Kunz, T. H., and Williams, J. B. (2012). Cutaneous water loss and lipids of the stratum corneum in two syntopic species of bats. Comp. Biochem. Physiol. A. 161, 208-215. doi: 10.1016/j.cbpa.2011.1 0.025

Muñoz-Garcia, A., and Williams, J. B. (2005). Cutaneous water loss and lipids of the stratum corneum in house sparrows Passer domesticus from arid and mesic environments. J. Exp. Biol. 208, 3689-3700. doi: 10.1242/jeb.01811

Muñoz-Garcia, A., and Williams, J. B. (2007). Cutaneous water loss and lipids of the stratum corneum in Dusky Antbirds, a lowland tropical bird. Condor 109, 59-66. doi: 10.1093/condor/109.1.59

Muñoz-Garcia, A., and Williams, J. B. (2011). Cutaneous water loss and the development of the stratum corneum of nestling House Sparrows (Passer domesticus) from desert and mesic environments. Physiol. Biochem. Zool. 84, 277-286. doi: $10.1086 / 659372$

Muñoz-Garcia, A., Cox, R. M., and Williams, J. B. (2008). Phenotypic flexibility in cutaneous water loss and lipids of the stratum corneum in House Sparrows 
(Passer domesticus) following acclimation to high and low humidity. Physiol. Biochem. Zool. 81, 87-96. doi: 10.1086/522651

Nicholson, S. E., Funk, C., and Fink, A. H. (2018). Rainfall over the African continent from the 19th through the 21 st century. Glob. Planet Change 165 , 114-127. doi: 10.1016/j.gloplacha.2017.12.014

Nilsson, J. - $\AA$, Molokwu, M. N., and Olsson, O. (2016). Body temperature regulation in hot environments. PLoS One 11:e0161481. doi: 10.1371/journal. pone. 0161481

Pattinson, N. B., Thompson, M. L., Griego, M., Russell, G., Mitchell, N. J., Martin, R. O., et al. (2020). Heat dissipation behaviour of birds in seasonally hot aridzones: are there global patterns? J. Avian Biol. 51:jav.02350. doi: 10.1111/jav. 02350

Piersma, T. (1998). Phenotypic flexibility during migration: Optimization of organ size contingent on the risks and rewards of fueling and flight? J. Avian Biol. 29, 511-520. doi: 10.2307/3677170

R Core Team. (2020). “R: A language and environment for statistical computing," in R Foundation for Statistical Computing, Vienna, Austria. Available at: https: //www.R-project.org/.

Ro, J., and Williams, J. B. (2010). Respiratory and cutaneous water loss of temperate-zone passerine birds. Comp. Biochem. Physiol. A. 156, 237-246. doi: 10.1016/j.cbpa.2010.02.008

Sapir, N., Tsurim, I., Gal, B., and Abramsky, Z. (2004). The effect of water availability on fuel deposition of two staging Sylvia warblers. J. Avian Biol. 35, 25-32. doi: 10.1111/j.0908-8857.2004.03212.x

Schaub, M., and Jenni, L. (2000). Fuel deposition of three passerine bird species along the migration route. Oecologia 122, 306-317. doi: 10.1007/ s004420050036

Schmaljohann, H., Liechti, F., and Bruderer, B. (2007). Songbird migration across the Sahara: the non-stop hypothesis rejected! Proc. R. Soc. B 274, 735-739. doi: $10.1098 / \mathrm{rspb} .2006 .0011$

Shirihai, H., Gargallo, G., and Helbig, A. J. (2001). Sylvia warblers: identification, taxonomy and phylogeny of the genus Sylvia. London: A\&C Black.

Shirihai, H., and Svensson, L. (2018). Handbook of Western Palearctic Birds, Volume 1: Passerines: Larks to Warblers. London: Bloomsbury Publishing.

Smit, B., Harding, C. T., Hockey, P. A. R., and McKechnie, A. E. (2013). Adaptive thermoregulation during summer in two populations of an arid-zone passerine. Ecology 94, 1142-1154. doi: 10.1890/12-1511.1

Smit, B., Zietsman, G., Martin, R. O., Cunningham, S. J., McKechnie, A. E., and Hockey, P. A. R. (2016). Behavioural responses to heat in desert birds: implications for predicting vulnerability to climate warming. Clim. Change Res. 3:9. doi: 10.1186/s40665-016-0023-2

Snow, D. W., Perrins, C. M., Hillcoat, B., Gillmor, R., and Roselaar, C. S. (1997). The birds of the Western Palearctic. Oxford: Oxford University Press.

Speakman, J. (1997). Doubly labelled water: theory and practice. Netherland: Springer Science \& Business Media.

Tieleman, B. I., and Williams, J. B. (1999). The role of hyperthermia in the water economy of desert birds. Physiol. Biochem. Zool. 72, 87-100. doi: 10.1086/ 316640

Tieleman, B. I., and Williams, J. B. (2002). Cutaneous and respiratory water loss in larks from arid and mesic environments. Physiol. Biochem. Zool. 75, 590-599. doi: $10.1086 / 344491$

Tsurim, I., Sapir, N., Belmaker, J., Shanni, I., Izhaki, I., Wojciechowski, M. S., et al. (2008). Drinking water boosts food intake rate, body mass increase and fat accumulation in migratory blackcaps (Sylvia atricapilla). Oecologia 156, 21-30. doi: 10.1007/s00442-008-0970-9

Vickery, J. A., Ewing, S. R., Smith, K. W., Pain, D. J., Bairlein, F., Škorpilová, J., et al. (2014). The decline of Afro-Palaearctic migrants and an assessment of potential causes. IBIS 156, 1-22. doi: 10.1111/ibi.12118
Walsberg, G. E., and King, J. R. (1978). The relationship of the external surface area of birds to skin surface area and body mass. J. Exp. Biol. 76, 185-189. doi: 10.1242/jeb.76.1.185

Weathers, W. W. (1981). Physiological thermoregulation in heat-stressed birds: Consequences of body size. Physiol. Zool. 54, 345-361. doi: 10.1086/physzool. 54.3.30159949

Webster, M. (1991). "Behavioral and physiological adaptations of birds to hot desert climates," in Proceedings of the 20th international ornithological congress (Oxford: Oxford University Press), 1765-1776.

Whitford, W. G., and Duval, B. D. (2020). Ecology of Desert Systems. Cambridge: Academic Press.

Whittow, G. C. (1986). "Regulation of Body Temperature," in Avian Physiology ed. P. D. Sturkie (New York, NY: Springer), 221-252. doi: 10.1007/978-1-46124862-0_9

Williams, J. B. (1996). A phylogenetic perspective of evaporative water loss in birds. Auk 113, 457-472. doi: 10.2307/4088912

Williams, J. B., and Tieleman, B. I. (2005). Physiological adaptation in desert birds. BioScience 55, 416-425. doi: 10.1641/0006-35682005055[0416:PAIDB] 2.0.CO;2

Wojciechowski, M. S., Kowalczewska, A., Colominas-Ciuró, R., and Jefimow, M. (2021). Phenotypic flexibility in heat production and heat loss in response to thermal and hydric acclimation in the zebra finch, a small aridzone passerine. J. Comp. Physiol. B 191, 225-239. doi: 10.1007/s00360-02001322-0

Wojciechowski, M. S., Yosef, R., and Pinshow, B. (2014). Body composition of north and southbound migratory blackcaps is influenced by the lay-ofthe-land ahead. J. Avian Biol. 45, 264-272. doi: 10.1111/j.1600-048X.2013. 00345.x

Wolf, B. O., and Walsberg, G. E. (1996). Respiratory and cutaneous evaporative water loss at high environmental temperatures in a small bird. J. Exp. Biol. 199, 451-457. doi: 10.1242/jeb.199.2.451

Yosef, R., and Chernetsov, N. (2005). Longer is fatter: body mass changes of migrant Reed Warblers (Acrocephalus scirpaceus) staging at Eilat. Israel. Ostrich 76, 142-147. doi: 10.2989/0030652050948 5486

Yousef, M. K., and Dill, D. B. (1971). Responses of Merriam's Kangaroo Rat to heat. Physiol. Zool. 44, 33-39. doi: 10.1086/physzool.44.1.30155550

Zuur, A., Ieno, E. N., Walker, N., Saveliev, A. A., and Smith, G. M. (2009). Mixed Effects Models and Extensions in Ecology with R. New York: Springer-Verlag, doi: 10.1007/978-0-387-87458-6

Conflict of Interest: The authors declare that the research was conducted in the absence of any commercial or financial relationships that could be construed as a potential conflict of interest.

Publisher's Note: All claims expressed in this article are solely those of the authors and do not necessarily represent those of their affiliated organizations, or those of the publisher, the editors and the reviewers. Any product that may be evaluated in this article, or claim that may be made by its manufacturer, is not guaranteed or endorsed by the publisher.

Copyright (c) 2021 Paces, Waringer, Domer, Burns, Zvik, Wojciechowski, Shochat, Sapir and Maggini. This is an open-access article distributed under the terms of the Creative Commons Attribution License (CC BY). The use, distribution or reproduction in other forums is permitted, provided the original author(s) and the copyright owner(s) are credited and that the original publication in this journal is cited, in accordance with accepted academic practice. No use, distribution or reproduction is permitted which does not comply with these terms. 